\title{
AVALIAÇÃO DOS PARÂMETROS DO PROCESSO TERMOMECÂNICO DA LAMINAÇÃO DE TIRAS A QUENTE DE AÇOS MICROLIGADOS AO NIÓBIO*
}

\author{
Melina Gamis da Silva ${ }^{1}$ \\ Ronaldo Antônio Neves Marques Barbosa² \\ Carlos Roberto Guinancio Carvalho ${ }^{3}$ \\ Felipe Monteiro Moraes de Moura Bastos ${ }^{4}$ \\ Jonathas Luis Groetares Ferreira ${ }^{5}$ \\ Marcelo Arantes Rebellato ${ }^{6}$ \\ Christien Guisard Hauegen ${ }^{7}$
}

\section{Resumo}

A evolução microestrutural que ocorre durante o processo de laminação a quente pode ser modelada em termos dos tamanhos de grão da austenita e de suas frações recristalizadas ao longo dos passes. Este artigo apresenta uma metodologia que permite a análise da cinética de recristalização e precipitação durante a laminação, com base na composição química do aço e parâmetros do processo. Essa metodologia pode ser utilizada na criação de modelos computacionais. Neste trabalho, as simulações apontaram para a alteração do teor de $\mathrm{Nb}$ e da temperatura de reaquecimento da placa como solução para otimizar o processo, resultando em melhorias no produto, ganho de produtividade e redução de custos.

Palavras-chave: Modelamento computacional; Laminação de tiras a quente; Aços microligados ao nióbio.

\section{EVALUATION OF THE THERMOMECHANICAL PROCESS PARAMETERS ON THE HOT STRIP ROLLING OF NIOBIUM MICROALLOYED STEELS}

\section{Abstract}

The microstructural evolution occurring during the hot rolling process can be modeled in terms of austenite grain size and recrystallized fractions during processing. This paper presents a methodology that allows the analysis of the kinetics of recrystallization and precipitation during rolling based on the chemical composition of the steel and process parameters. This methodology can be applied to create computational models. In this work, the simulations indicated that changes in $\mathrm{Nb}$ content and reheating temperature as a solution to optimize processes resulting in product improvements, productivity gains and cost savings.

Keywords: Computational Model; Hot strip rolling; Nb microalloyed steels.

Engenheira Metalúrgica, Mestranda, Companhia Siderúrgica Nacional, Volta Redonda, RJ, Brasil.

2 Engenheiro Mecânico, Doutor, Professor, Departamento de Engenharia Metalúrgica e de Materiais, UFMG, Belo Horizonte, MG, Brasil.

3 Engenheiro Metalúrgico, Mestre, Companhia Siderúrgica Nacional, Volta Redonda, RJ, Brasil.

4 Engenheiro Mecânico, Mestrando, UFMG, Belo Horizonte, MG, Brasil

5 Estudante de Engenharia Metalúrgica, Engenheirando, UFF, Volta Redonda, RJ, Brasil.

6 Engenheiro Metalúrgico, Consultor, Companhia Brasileira de Metalurgia e Mineração, São Paulo, $S P$, Brasil.

7 Engenheiro Metalúrgico, Mestre, Companhia Siderúrgica Nacional, Volta Redonda, RJ, Brasil. 


\section{INTRODUÇÃO}

Aços de alta resistência, elevada ductilidade e tenacidade têm sido estudados por pesquisadores em todo o mundo. Na maior parte dessas pesquisas, os fundamentos da metalurgia física desses aços são abordados. Por exemplo, Morales et al [1] avaliaram as contribuições que os diversos mecanismos de endurecimento trazem ao valor do limite de escoamento de um aço microligado. Nayaka et al [2] estudaram os aspectos da microestrutura de aços microligados para tubos da classe API. Este é também o tópico abordado por $\mathrm{Hu}$ et al para placas laminadas a quente empregando-se dois estágios de resfriamento [3]. Outro exemplo, é o trabalho de Misra et al [4] onde a evolução da microestrutura durante processamento similar ao tratamento termomecânico clássico (TTMC) é descrita em detalhes. Alguns autores propõem novas rotas de fabricação e novas composições químicas. É o caso de Wu et al [5] onde um TTMC é aplicado, seguido de têmpera e revenimento, em aços médio carbono, $0,30 \%$ de carbono, produzindo limite de escoamento tão elevado quanto $1800 \mathrm{MPa}$ e tenacidade de $30 \mathrm{~J} \mathrm{a}-20^{\circ} \mathrm{C}$. Como se vê, são contribuições variadas e relevantes. Entretanto, apesar de significativos e de ajudarem ao melhor entendimento da metalurgia física associada ao processo de laminação a quente, esses conhecimentos não são tão facilmente transportados diretamente à realidade de uma linha de laminação industrial.

A laminação de tiras a quente é complexa do ponto de vista dos fundamentos da metalurgia física. Isto porque há várias possibilidades de evolução da microestrutura notadamente durante o estágio de acabamento. Por exemplo, a deformação aplicada em um passe pode ser transferida aos demais, em sucessão, levando a recristalização dinâmica (RXD) e metadinâmica (RXMD). Por outro lado, se a temperatura do primeiro passe de acabamento se encontrar baixa, as deformações podem, eventualmente, se acumularem sem, todavia, ativar RXD. Neste caso, os grãos de austenita podem ser encruados em passes sucessivos, de modo muito similar ao que ocorre no acabamento em um laminador de chapas grossas. Há ainda uma possibilidade intermediária onde a microestrutura se encontraria parcialmente recristalizada e parcialmente encruada. Neste caso, o passe seguinte seria aplicado sobre uma microestrutura mista, onde se encontrariam austenita recristalizada e outra somente recuperada estaticamente. Como se vê, as possibilidades são variadas e complexas.

As variações acima apontadas afetam a estabilidade do trem acabador do laminador de tiras a quente [6]. É possível também que essas diferentes possibilidades de microestruturas afetem o tamanho médio e a distribuição dos grãos de ferrita a temperatura ambiente. Entretanto, não há como se averiguar o estado da austenita, fisicamente, por amostragem e têmpera, por exemplo, entre cadeiras do laminador. A alternativa é por meio do modelamento da evolução da microestrutura, como se apresenta neste trabalho.

Um dos objetivos deste trabalho é apresentar uma metodologia de avaliação dos parâmetros de uma linha de laminação de tiras a quente, no modelamento da evolução da microestrutura de aços microligados ao nióbio. Através dessa metodologia, foi criado um modelo que está sendo validado com dados de corridas industriais. 


\section{DESCRIÇÃO DE UM CASO: PROCESSO DE LAMINAÇÃO DE TIRAS A QUENTE DA CSN}

Corridas industriais foram realizadas nas instalações da Companhia Siderúrgica Nacional (CSN) com o objetivo de estudar a melhor prática de temperatura de extração dos fornos de reaquecimento de placas do laminador de tiras a quente, $L T Q$, de aços ARBL microligados com $\mathrm{Nb}$, além de visar redução de tempo de parada do esboço na entrada do trem acabador com consequente aumento de produtividade na laminação a quente desses aços.

O LTQ da CSN possui capacidade de produção de 5,1 milhões de toneladas ao ano de BQ's com espessuras nominais entre 1,2 e 12,7 mm e larguras entre 715 e $1575 \mathrm{~mm}$. O LTQ possui tecnologias para controles de temperaturas, dimensão, forma e qualidade superficial das tiras. A Figura 1 mostra o "lay-out" básico do LTQ.

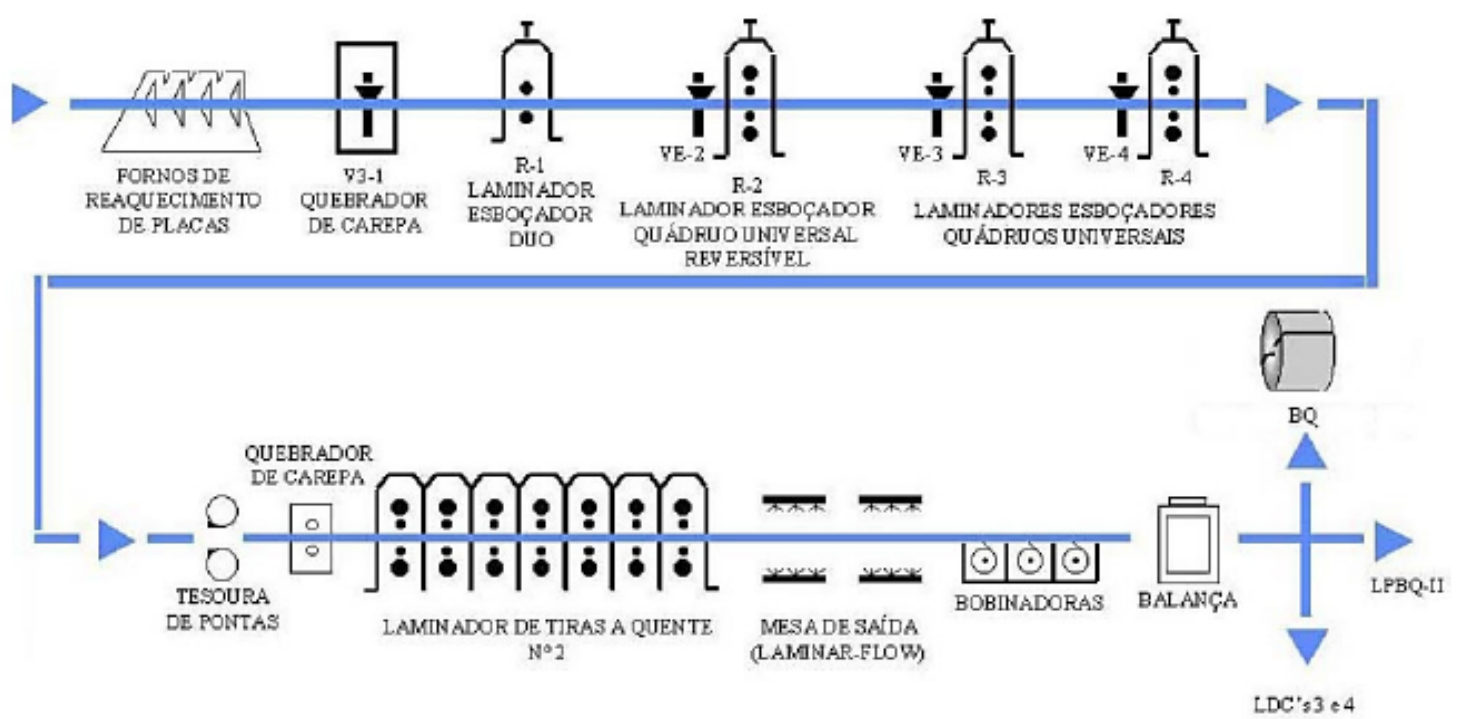

Figura 1. Configuração da linha de tiras a quente da CSN.

Placas são reaquecidas em quatro fornos do tipo vigas caminhantes com capacidade de $250 \mathrm{t} / \mathrm{h}$. Elas são extraídas dos fornos a uma temperatura mínima de $1150^{\circ} \mathrm{C}$, variando de acordo com o tipo de aço. As placas têm espessura de $257 \mathrm{~mm}$ na saída do forno e larguras na faixa de 830 a $1620 \mathrm{~mm}$. Os comprimentos padrões podem estar entre 5250 e $10500 \mathrm{~mm}$.

A laminação de desbaste é realizada em trem desbastador ou esboçador com quatro cadeiras verticais (para laminação de bordas) e quatro cadeiras horizontais (para redução contínua da espessura). A primeira cadeira é do tipo duo contínua (R1), onde o laminador vertical (que reduz a largura) e o laminador horizontal (que reduz a espessura) são separados. Em seguida, tem-se uma cadeira do tipo quádruo reversível universal (R2) que pode aplicar até 07 passes consecutivos (usualmente 5 passes), e duas cadeiras quádruo universais (R3 + R4) conjugadas que concluem a produção do esboço de laminação. Nessa seção existem sistemas de descarepação por jatos de água de alta pressão acoplados às cadeiras (nas entradas de todos os passes), bem como sistemas de monitoramento e controle contínuo do processo de produção e temperatura. A espessura final do esboço é de aproximadamente $35 \mathrm{~mm}$ após o último passe da laminação de desbaste. A temperatura do material após essa etapa se encontra usualmente entre 1000 e $1100^{\circ} \mathrm{C}$. Os pirômetros nessa etapa estão localizados no início e final do desbaste. 
A laminação de acabamento ocorre em trem acabador com sete cadeiras de laminação do tipo quádruo em tandem, com sistema de descarepação na entrada do trem e pirômetros na entrada e saída do laminador. A velocidade de atravessamento depende do tipo de aço e dimensão produzida, podendo chegar a $1300 \mathrm{mpm}$ na última cadeira. As temperaturas de entrada e de saída do trem acabador dependem do material que está sendo processado; em geral se encontram acima de $980^{\circ} \mathrm{C}$ na entrada e abaixo de $950^{\circ} \mathrm{C}$ na saída da última cadeira. As laminações de aços com $\mathrm{Nb}$ têm a particularidade de necessitar da prática de um tempo de espera entre as seções de desbaste e de acabamento, suficiente para se atingir a faixa de temperatura de precipitação de partículas com $\mathrm{Nb}$.

A seção de resfriamento acelerado localiza-se entre a última cadeira do trem acabador e as bobinadeiras. A temperatura nessa seção é reduzida pela aplicação, em ambas as faces da tira, de água em jatos tipo "laminar flow" através de 14 bancos de chuveiros. A temperatura final é especificada em função do tipo de material e das características metalúrgicas desejadas na bobina a quente. Ao final deste resfriamento, as tiras são bobinadas em três bobinadoras do tipo pneumáticas capazes de bobinar todos os aços produzidos em todas as dimensões do portfólio de produtos comercializados.

\section{DESCRIÇÃO DO MODELO DE EVOLUÇÃO DE GRÃO AUSTENÍTICO}

O modelo se fundamenta em alguns módulos que são computados ao longo do histórico de processamento industrial ou sequência de passes de um dado produto. Nesses módulos, cálculos específicos do processo industrial são executados. 0 objetivo aqui é responder algumas perguntas relevantes ao processo e auxiliar os envolvidos diretamente com a linha de laminação. Alguns exemplos são listados a seguir.

Forno de reaquecimento: Conhecida a temperatura usual de um forno de reaquecimento, definida em função das várias características operacionais da linha de laminação, qual seria o teor de $\mathrm{Nb}$ que estaria sendo dissolvido? Caso a temperatura de um forno pudesse ser alterada, qual seria a temperatura mínima desse forno de tal que todo $\mathrm{Nb}$ presente no aço se encontrasse dissolvido na matriz antes de se iniciar a laminação?

Laminação de desbaste: Nesta etapa, os fenômenos relevantes dizem respeito à recristalização estática e ao crescimento de grão entre cadeiras. A ideia básica seria a de se terminar essa etapa de laminação com uma microestrutura homogênea ao longo da secção transversal do esboço e com um tamanho de grão austenítico o mais refinado possível. Perguntas típicas a serem respondidas seriam, por exemplo: qual seria a menor redução total na espessura no desbaste que levaria ao menor tamanho de grão de austenita ao final do desbaste? Essa redução total garante homogeneidade de microestrutura ao longo de toda secção transversal do esboço ou haveria regiões com grãos grosseiros e outras com grãos finos produzindo uma microestrutura heterogênea? Além disso, qual seria o tamanho de grão de austenita deixando o desbaste e entrando no acabamento?

Laminação de acabamento: Nesta etapa, os acontecimentos importantes dizem respeito ao condicionamento da austenita antes da transformação de fases da austenita para ferrita, na linha de chuveiros. As questões importantes se relacionam à possibilidade de ocorrência de precipitação durante ou após acabamento e à deformação acumulada na austenita antes da transformação de fases. Qual seria o grau de deformação acumulada por esta austenita, caso alguma deformação fosse 
acumulada? Há possibilidade de ocorrer RXD em alguma cadeira do acabador? Quais seriam as consequências ao controle do laminador caso isso acontecesse?

Transformação de fases: Nesta etapa, definido o estado da austenita entrando na linha de chuveiros, isto é o tamanho de grão médio da austenita e a deformação acumulada antes da transformação, o relevante seria determinar a taxa média de resfriamento na linha de chuveiros. A pergunta fundamental diz respeito a qual tamanho de grão ferrítico será obtido. Outra pergunta importante seria sobre o estado desta ferrita. Por exemplo, ela seria uma ferrita poligonal, sem deformação? Ou ela seria uma ferrita deformada? Poderia se ter uma situação em que haveria uma mistura de pelo menos dois tipos de ferrita: uma não deformada e outra deformada gerando uma microestrutura heterogênea?

Essas e outras questões importantes ao processo no que diz respeito a projeto de liga, controle do laminador e microestrutura da austenita e da ferrita poderiam ser estudadas usando o modelo aqui apresentado como uma ferramenta auxiliar às práticas operacionais, com será mostrado mais à frente.

\section{DADOS DE ENTRADA E DE SAÍDA}

\subsection{Dados de Entrada}

Há pelo menos duas situações distintas e importantes aos técnicos envolvidos na laminação. Num caso, o que se deseja seria simular uma condição real, ocorrendo na linha de laminação. Noutra, a situação seria a de análise de possibilidades. Nos dois casos, as variáveis importantes são apontadas a seguir.

No forno de reaquecimento: a) composição química; b) temperatura da zona de encharque e período de tempo durante o encharque. Antes do primeiro passe de desbaste: qual seria o tamanho de grão inicial da austenita saindo do forno de encharque?

Durante 0 segundo passe de desbaste e subsequentes: quais seriam as temperaturas e as reduções em cada passe de laminação? Após cada passe: quais seriam as velocidades de laminação e os tempos entre reduções? Em particular, no desbaste, esses passes são aplicados com reversões da placa. Os tempos entre deformações variarão dependendo do local onde se encontra um ponto de referência ao longo do comprimento da placa. Numa primeira simulação, toma-se sempre o ponto de referência como aquele localizado à metade do comprimento, largura e espessura da placa. Após último passe de desbaste: qual seria o tempo de transferência entre passe e o primeiro da cadeira acabadora?

No acabamento, durante todos os passes: quais seriam as temperaturas, as reduções, as velocidades de laminação e a distância até a cadeira subsequente? Após último passe de acabamento: qual seria o tempo necessário para se atingir a linha de chuveiros? A que temperatura a tira chega ao início da linha de chuveiros? De novo, deve-se ter aqui um ponto de referência na tira na obtenção desses dados. Numa primeira simulação, deve-se tomar o ponto médio geométrico ao longo do comprimento da tira como referência.

$\mathrm{Na}$ saída da linha de chuveiros: qual é o período de tempo a que a tira fica no resfriamento na linha de chuveiros? Qual é a temperatura da tira, no ponto de referência, na saída da tira?

$\mathrm{Na}$ obtenção dos dados acima, não se pode generalizar um procedimento que seja adequado a todos os tipos de laminadores; cada caso é, de fato, um caso. Entretanto, alguns dados são mais importantes que outros no que se refere a 
incertezas nas medições. As medições das temperaturas são as de maior importância. Essas devem ser realizadas com muito cuidado uma vez que elas influenciarão em larga escala nas previsões do modelo. $\mathrm{Na}$ maior parte dos laminadores atuais, há dados no nível 2 de automação que são muito úteis. Rotinas de extração automática desses dados podem ser desenvolvidas, uma vez que se tenha feito a verificação das previsões destes modelos com os valores medidos dos pirômetros disponíveis.

\subsection{Dados de Saída}

Alguns possíveis dados de saída gerados nas simulações são os listados a seguir. Dados referentes à condição da microestrutura durante e após processamento: Ocorreu recristalização estática total a cada passe de desbaste ou houve formação de estruturas mistas de austenita recristalizada e não recristalizada? Qual era o estado da austenita sendo transferida à etapa de acabamento: totalmente recristalizada ou parcialmente recristalizada? Houve crescimento de grão significativo entre período de transferência? Houve formação de precipitados de $\mathrm{Nb}$ durante o processo? Se positivo, quando foi que ocorreu essa precipitação; antes, durante ou após acabamento? Houve encruamento da ferrita na transformação de fases?

Dados referentes ao processo: A temperatura de forno é a mais indicada? As temperaturas de início e de fim de desbaste são as mais apropriadas? O mesmo se pergunta sobre a etapa de acabamento; as temperaturas de início e de final de acabamento são as mais apropriadas? A sequência de reduções aplicada nos passes é a mais favorável?

Essas são algumas das informações que podem ser obtidas das simulações, não se pretendo ser aqui exaustivo; há mais possibilidades.

\section{ANÁLISE DE CASO}

As Tabelas e gráficos abaixo mostram os resultados obtidos na análise de um caso de laminação no laminador de tiras a quente da CSN. As Tabelas 1 e 2 mostram, respectivamente, a composição química da placa laminada e um sumário dos dados de processo.

Tabela 1. Composição química para o Caso 1

\begin{tabular}{|c|c|c|c|c|c|c|c|}
\hline Elemento & $\mathrm{C}$ & $\mathrm{Mn}$ & $\mathrm{Si}$ & $\mathrm{Al}$ & $\mathrm{Nb}$ & $\mathrm{Cr}$ & $\mathrm{N}$ \\
\hline Teor $[\%]$ & 0,100 & 0,530 & 0,005 & 0,032 & 0,024 & 0,020 & 0,004 \\
\hline
\end{tabular}

Tabela 2. Dados iniciais de processo

\begin{tabular}{|c|c|}
\hline Parâmetro & Valor \\
\hline Espessura da Placa [mm] & 257 \\
\hline Largura da Placa [mm] & 1200 \\
\hline Comprimento da Placa [mm] & 10500 \\
\hline Espessura da Tira [mm] & 6,00 \\
\hline Largura da Tira [mm] & 1200,0 \\
\hline Temperatura de Reaquecimento $\left[{ }^{\circ} \mathrm{C}\right]$ & 1198 \\
\hline Tamanho de Grão Inicial $[\mu \mathrm{mm}]$ & 150 \\
\hline $\mathrm{T}_{\mathrm{s}} \mathrm{AcC}\left[{ }^{\circ} \mathrm{C}\right]$ & 883 \\
\hline $\mathrm{T}_{\mathrm{f}} \mathrm{AcC}\left[{ }^{\circ} \mathrm{C}\right]$ & 602 \\
\hline$\Delta \mathrm{t}_{\mathrm{AcC}}[\mathrm{s}]$ & 15,7 \\
\hline
\end{tabular}


Como dados de entrada são inseridos, inclusive, dados da sequência de passes de laminação em cada cadeira tais como distâncias entre cilindros, velocidades tangenciais dos cilindros de trabalho, temperaturas e tempos de intervalo, diâmetros dos cilindros de trabalho e cargas de laminação.

A Figura 2 mostra um sumário de uma análise metalúrgica realizada considerando os dados apresentados nas Tabelas 1 e 2.

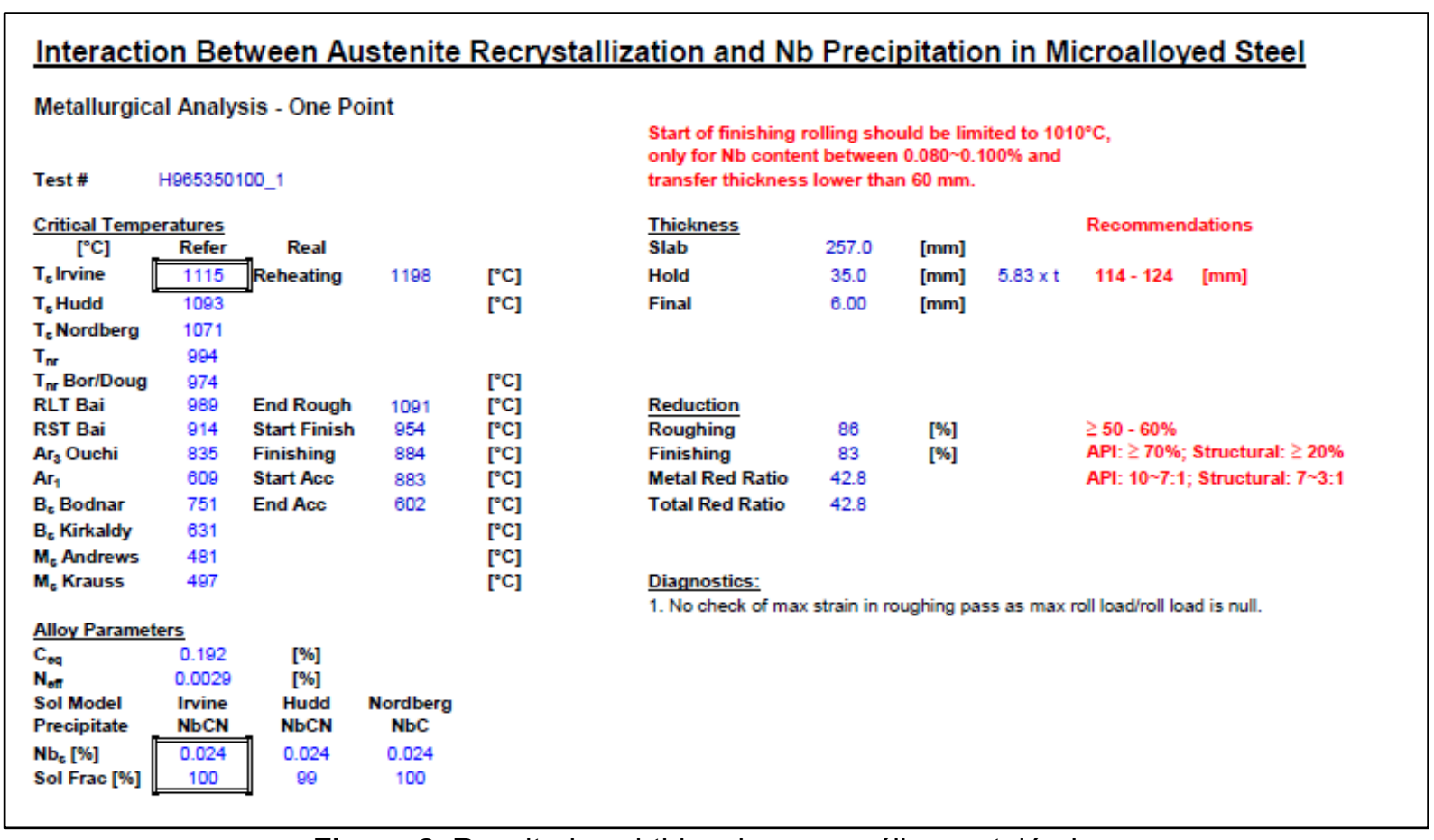

Figura 2. Resultados obtidos de uma análise metalúrgica

A Figura 3 mostra os resultados obtidos para cálculos da fração recristalizada após um dado passe de laminação. Nota-se que o modelo indica que a austenita se recristalizou $100 \%$ no desbaste enquanto, no acabamento, a previsão é de que haja recristalização parcial.

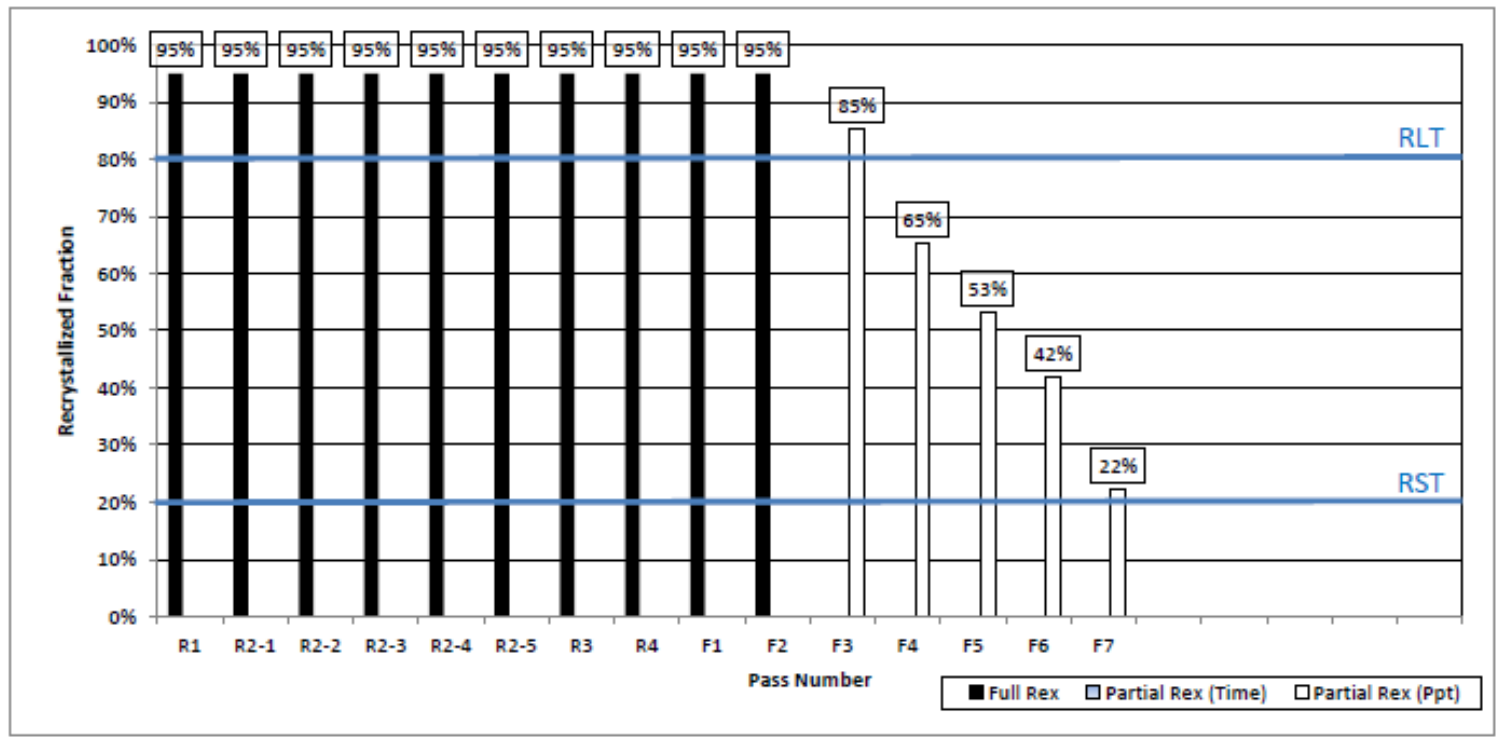

Figura 3. Fração recristalizada após cada passe de laminação. 


\section{DISCUSSÃO}

A austenita parcialmente recristalizada pode gerar tamanhos de grãos de ferrita heterogêneos. Talvez essa situação melhorasse caso, por exemplo, a temperatura de início de acabamento fosse abaixada em $30^{\circ} \mathrm{C}$. Neste caso, o resultado do modelo é o que se mostra na Figura 4.

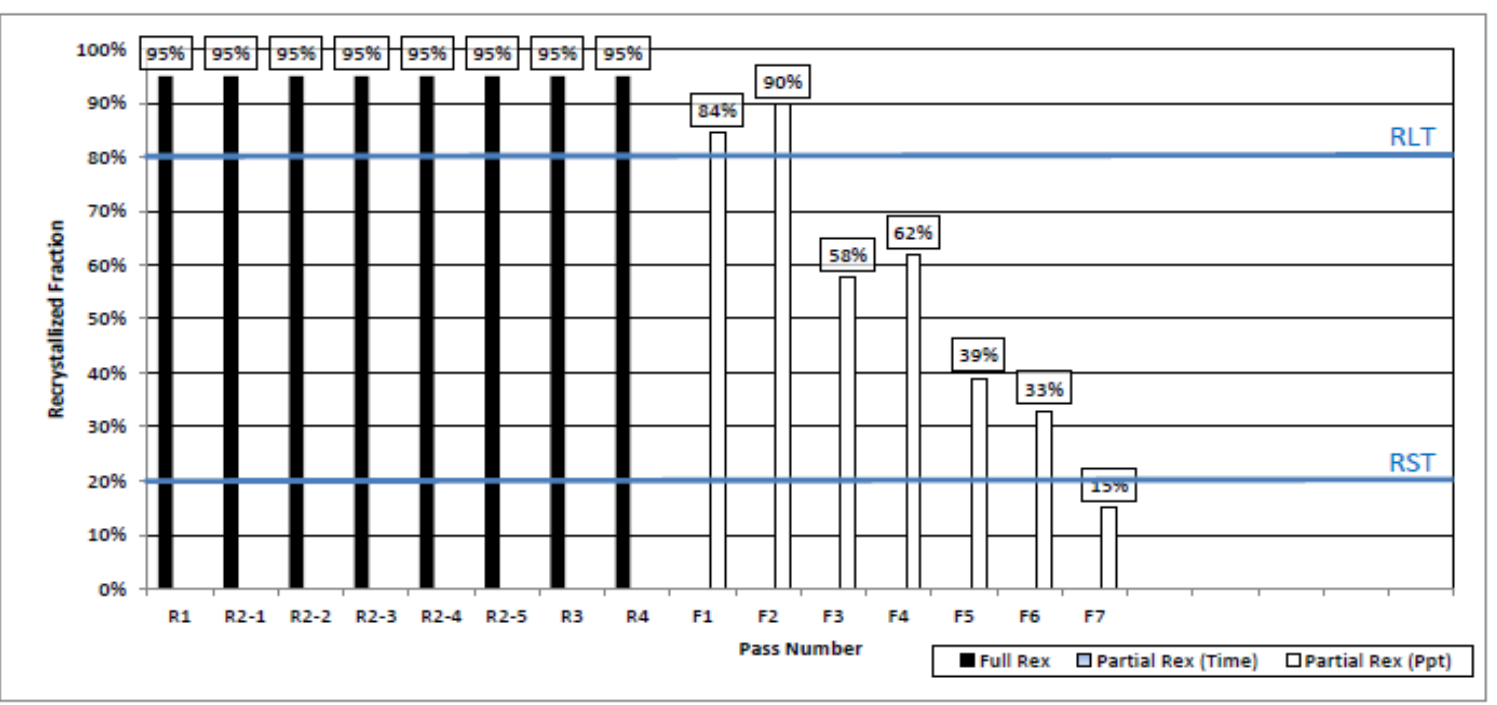

Figura 4. Fração recristalizada após cada passe de laminação. Temperatura de início de acabamento foi reduzida de $30^{\circ} \mathrm{C}$.

Neste caso, o modelo mostra que as frações recristalizadas permanecem similares à condição anterior.

Uma solução que não diminua a produtividade da linha seria, por exemplo, aumentar a eficácia do $\mathrm{Nb}$, passando-o de 0,027 para 0,034 . Os resultados são os mostrados na Figura 5. Neste caso, a situação é melhor do que a apresentada na Figura 3 e não há redução de produtividade nem riscos de se laminar abaixo de Ar3. As simulações mostram ainda que o teor de $0,034 \mathrm{Nb}$ poderia ser colocado em solução a uma temperatura de forno de reaquecimento de $1150^{\circ} \mathrm{C}$ e não os atuais $1198^{\circ} \mathrm{C}$, trazendo um bônus adicional ao processo.

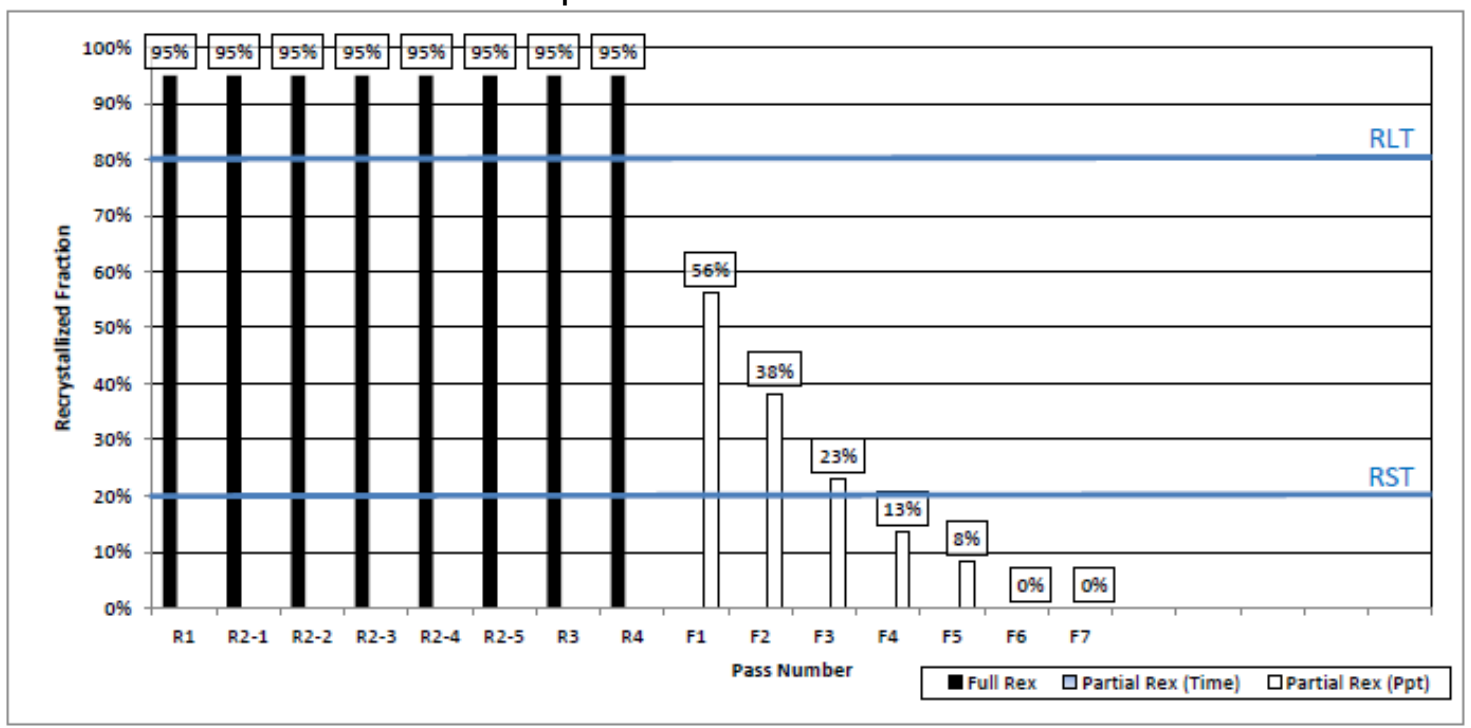

Figura 5. Fração recristalizada após cada passe de laminação. Teor de $\mathrm{Nb}$ foi avariado de 0,027 para $0,034 \%$ em peso. 
As simulações preliminares mostradas acima indicam que o modelo pode auxiliar na identificação de potenciais ganhos na linha de laminação, por exemplo, na produtividade e temperatura de reaquecimento.

\section{CONCLUSÕES}

Um modelo computacional foi desenvolvido com a metodologia apresentada, e aplicado para simular uma condição padrão de laminação industrial realizada na CSN e também duas condições alternativas, visando melhoria do processo. No caso específico, foram analisadas, primeiramente, a possibilidade de se reduzir as temperaturas nos passes de acabamento e então, o incremento do teor de $\mathrm{Nb}$ da liga. As simulações indicam a possibilidade de melhoria do processo com a utilização da Temperatura de Reaquecimento a $1150^{\circ} \mathrm{C}$ e teor de $0,034 \mathrm{Nb}$. Os próximos passos deste projeto deverão envolver novos testes nas condições sugeridas pelo modelo.

\section{REFERÊNCIAS}

1 Morales, EV, Silva, RA, Bott, IS, Paciornik, S. Strengthening mechanisms in a pipeline microalloyed steel with a complex microstructure. Materials Science \& Engineering A. 2013, 585: 253-260.

2 Nayaka, SS, Misra, RDK, Hartmann, J, Siciliano, F, Gray, JM. Microstructure and properties of low manganese and niobium containing HIC pipeline steel, Materials Science and Engineering A. 2008, 494: 456-463.

$3 \mathrm{Hu}, \mathrm{J}, \mathrm{Du}, \mathrm{L}-\mathrm{X}$, Wang, J-J, Xie, H., Gao, C-R, Misra, RDK. Structure-mechanical property relationship in low carbon microalloyed steel plate processed using controlled rolling and two-stage continuous cooling, Materials Science \& Engineering A. 2013, 585: 197-204.

4 Misra, RDK, Nathania, H, Hartmann, J, Siciliano, F. Microstructural evolution in a new $770 \mathrm{MPa}$ hot rolled $\mathrm{Nb}-\mathrm{Ti}$ microalloyed steel, Materials Science and Engineering A. 2005, 394: 339-352.

$5 \mathrm{Wu}, \mathrm{H}$, Ju, B, Tang, D, Hu, R, Guo, A, Kang, Q, Wang, D. Effect of Nb addition on the microstructure and mechanical properties of an $1800 \mathrm{MPa}$ ultrahigh strength steel, Materials Science \& Engineering A. 2015, 622: 61-66.

6 Jonas, JJ. Hot strip mill as an experimental tool, ISIJ International, 2000, 40: 731-738. 